\title{
The Study of Transforming Manufacturing Firms into Service-oriented Business: An SSME Perspective
}

\author{
Yixin Zhou and Zhen Guo \\ Harbin University of Commerce, Harbin city, Heilongjiang Province, China \\ 406809481@qq.com
}

\begin{abstract}
Keywords: Service science; Management and engineering (SSME); Service innovation; Business
\end{abstract} transformation; Service-oriented

\begin{abstract}
The purpose of this study is to explore how the three northeastern provinces of enterprises manufacturing firms develop competitive advantages via providing value-added innovative services and how they transform themselves into service-oriented businesses in China. Through research to obtain data which was analyzed by AMOS .Our results indicated that the manufacturing companies have realized that they are also service providers and are capable of utilizing IT technology to build the service platform to transform themselves into service-oriented businesses.
\end{abstract}

\section{Introduction}

China's economy showing that the main force of the economy has been labor-intensive industries to knowledge-intensive industries, the era of service economy is moving forward. In the past, three provinces in Northeast China's economic development policy and resource allocation were mostly manufacturing-oriented. In recent years, the country begin to promote the manufacturing and service development of the two-wheel drive development model[1].The Northeast region has a wealth of manufacturing experience, there are many complementary and production support or internal service forces, which have the power to produce the necessary characteristics of the manufacturing industry[2].

After entering the 21st century, rapid development of service industries and globalization. IBM observed the gradual transformation of the entire economic model. It would reorganize the internal organization and direction, combined with scientific and professional competence and business, which could have ability to solve the problem of innovation to business problems. The emerging disciplines of the era are called Services Science, Management, and Engineering (SSME), or "Services Science." Service Science is a multidisciplinary field of integration that integrates the concepts of technology, business, and social sciences, and uses business strategies, processes, and talent to assist in business transformation, strategic goals, and business models [3].

"Service Science" is through the integration of different areas of theory, putting forward innovative systematic solutions for enterprises to creating a new value [4]. This paper explores the transition from manufacturing to service-oriented enterprise, which is in line with the interdisciplinary subject of service science, which aims to solve the problem of service in enterprises [5]. Therefore, through the discussion of related literature, this paper wants to understand the service innovation of manufacturing industry. The specific research objectives are as follows:

(1) Establishing a theoretical framework from the perspective of integrated service science, which can explore how firms provide value-added services through service innovation and carry out business transformation activities.

(2) Through the empirical research, we can understand the impact of service innovation on process design, partnership and enterprise in the course of transforming into service oriented enterprise in our country. 


\section{Review}

Abort the definition of service science, scholars put the following views: Abe [6]: Service science and business are inseparable relationship. From the viewpoint of the service provider, expect to improve the productivity of the commercial activities of the service; and reduce the risk by increasing the forecast of the future business on the customer's point of view. Therefore, service science can continue to grow by improving the capabilities of the enterprise. Hertog [7] proposed four facets of service innovation to represent the relationship between innovative service activities and explorations in knowledge-intensive business services. The four facets interact with each other.(1) New client interface; (2)Service delivery system; (3) new service concept; (4) technological option. In order to adapt to the external environment and internal management changes, enterprises based on vision and future development goals, will face the need for transformation. Venkatraman [8] proposed the application of information technology as a basis for enterprise transformation strategy to transform the level and potential benefits as a facade, which can be divided into the following five levels: (1) local exploitation;(2) internal integration;(3) business process redesign;(4) business network redesign;(5)business scope redefinition. Gonzalez and Garazo [9] define the organization's service orientation as: Organizing a series of activities which is designed to create and deliver good services. Enterprises must be able to do business with the needs of change. To implement this goal, two most important initiators in business operations are the componentization and service orientation of business processes. In other words, a single department for each business process has its purpose and function, making it easier to deliver the service, and integrating the link between each component is "service oriented."

\section{Research Design}

In this paper, Hertog (2000) proposed the service innovation aspect to verify the relationship between manufacturing and service innovation activities. In the process of enterprise transformation, the paper argues that China's manufacturing industry should not only affect the local organizational functions but also have a greater impact on the process, partnership and enterprise. Therefore, referring to Venkatraman (1994), "Business Process Reengineering", "Enterprise Network Redesign" and "Re-definition of Enterprise Category", which are based on information technology to promote enterprise transformation.

The Impact of IT Capabilities on Service Innovation Dimensions. Based on Hertog (2000) that the technical aspects of the service industry in the industry as an unnecessary option. The paper to verify the manufacturing sector in the service activities in the information technology as a necessary tool to assist enterprises to develop services, it is proposed three Inference:(1) The manufacturer's IT capabilities have a positive relationship with the customer interface for the development of services.(2) The manufacturer's IT capabilities have a positive relationship to the delivery system of development services.(3) The IT capabilities of manufacturers have a positive relationship to the concept of service development.

The Impact of Service Innovation on Enterprise Transformation Level. The customer interface refers to the way of service is provided to the customer and the way of communicating and cooperating with the customer [10]. Service innovation of the customer interface refers to the service provider and customer interaction between the interface innovations. It is mainly for the promotion and customer communication quality and participation in the process of service that resulting in service innovation. However, the level of innovation required for different customer-facing interfaces. Therefore, this paper puts forward the following inference:(4) The innovation level of the manufacturer's customer interface has a positive effect on the enterprise transformation level.(4.1) The degree of innovation in the manufacturer's customer interface has a positive effect on business process redesign.(4.2) The degree of innovation in the customer interface of the manufacturer has a positive effect on the enterprise network redesign.(4.3) The degree of innovation of the manufacturer's customer interface has a positive effect on the definition of the enterprise category. 
Delivery system and customer interface are closely related. But they are mainly the internal organization of the arrangements and planning. Therefore, this paper puts forward the following inference:(5) The innovation level of the manufacturer's delivery system has a positive effect on the level of enterprise transformation.(5.1) The degree of innovation of the manufacturer's delivery system has a positive effect on business process redesign.(5.2) The degree of innovation of the manufacturer's delivery system has a positive impact on enterprise network redesign.(5.3) The degree of innovation of the manufacturer's delivery system has a positive effect on the definition of the enterprise category[11].

The concept of service may be presented in the form of ideas or concepts, especially innovative services that have not yet been developed. So the new or improved service concept may create a new markets, the new customers and pre-emptive than the past. The service plays a greater value. (6) The innovation degree of manufacturer's service concept has a positive effect on the transformation level of enterprises.(6.1) The degree of innovation in the manufacturer's service concept has a positive effect on business process redesign.(6.2) The degree of innovation of the manufacturer's service concept has a positive effect on the re-engineering of the enterprise network.(6.3) The degree of innovation of the manufacturer's service concept has a positive effect on the definition of the enterprise category.

Questionnaire Survey. The questionnaire design is mainly based on the four aspects of service innovation proposed by Hertog (2000), and the theory of enterprise transformation level proposed by Venkatraman (1994) as the theoretical basis of the problem, and using Likert 5-point scale, Respectively, to "very disagree" to give a "very agree" to give 5 points. The main research objects for the transformation of the three northeastern provinces of China manufacturers, and from the selection of innovative products in addition to manufacturing production, but also provide quality service to customers of the manufacturers [12]. The survey lasted one month. A total of 360 questionnaires were distributed, 146 replies and 130 valid questionnaires.

\section{Statistical Analysis}

In this paper, 130 valid sample questionnaire data were made descriptive statistical analysis. The results are as follows.

Manufacturing Types. In this paper, according to the National Bureau of Statistics published a classification of the manufacturing industry a total of 31 categories. Deleted the research data which were not released in the type, and summarized in this paper the manufacturing sector for the 9 categories. The largest number of general equipment manufacturing industry sample number was $35 \%$.

Services Provided by the Manufacturer. 88 samples of $\mathrm{R} \& \mathrm{D}$ design services were provided in the collected samples, accounting for 35\%.And followed by 61 samples(25\%) with integrated solutions and 49 (20\%) with technical evaluation services.

The Purpose for which the Manufacturer Develops the Service. This paper summarized the manufacturer's views and literature. The purpose of the development of services was divided into six. Other items were open-ended questions for respondents, which were not covered in the questionnaire. Among them, the main reasons for the development of services were to enhance competitiveness, customer needs, enhance added value and improve customer loyalty.

The Advantages of Manufacturers to Develop Services. The results of the survey showed that the advantages of the manufacturers' development services lied in their strong integration (accounting for 27.39\%), unique content of services (accounting for 26.96\%) and cross-field (accounting for $16.09 \%$ ).

\section{Empirical Analysis}

In this paper, we used AMOS7.0 statistical software to analysis 130 valid samples of estimation tools and established the path map. 
An Empirical Estimate of Customer Interface Model (I). The linear structure of the customer interface model (1) was used to investigate the impact of IT capabilities on the positive relationship between the customer interface and the manufacturer, and further understand the customer interface innovation level of enterprise transformation of the three levels had a direct impact relationship.

The first estimate of the normalized parameter estimate was less than 0.95 , indicating that there was no violation of the estimated problem. And then by the size of the standard error, to determine whether there was a model of the estimated problems or instability. All the parameters of the customer interface were shown by the results to be significant levels of $p<0.0010$.It indicated that the assumptions associated with the facets of the customer interface assumed a positive relationship.

After the parameters were evaluated, the overall fitness had evaluated. The results showed that the empirical model of customer interface was a good matching model.

An Empirical Estimate of the Transfer System Model (II). The same hypothesis verification resulted of the delivery system model (I) could be obtained by the same estimation method of the customer interface model (II). The results showed that $\mathrm{p}=0.002<0.05$. For the chi-squared value, while the RMSEA was between 0.05 and 0.1 , which was grayed-out and unsatisfactory but could acceptable. The results showed that the transfer system model (II) and the data fitted poorly, did not fully meet the evaluation criteria.

An Empirical Estimate of Service conceptual Model (III). The same method was used to estimate the linear structure of the service conceptual model (III). All parameters were significant ( $\mathrm{p}$ $<0.001$ ). This hypothesis, which was related to the facets of the service concept, assumed a positive relationship. And the results of fitness evaluation were all in accordance with the fitness of the evaluation standard. Service model of the theoretical framework for the concept of good fitted model.

An Empirical Estimate of Service Innovation Model (IV). The results of parametric estimation among the variables of service innovation showed that the information technology capability had more than one parameter to the facet of the transmission system. The IT capabilities of the customer interface and service concept parameters were less than 0.95. And it passed a significant level of $\mathrm{p}<0.001$,but the parameters of the latent variables for all observed variables also reached a significant level. However, the innovation level of the service innovation had no significant, on which affected the transformation level of the enterprise.

Results. From the relationship between the variables test, the results showed that all three corollaries were true. This implied that IT capabilities had a significant positive relationship with the customer interface, delivery system and service concept. For the service innovation to the transformation level, the service innovation model IV contradicted the findings of the previous three models. The effect of service innovation on the transformation activity was significant, but when all potential variables were considered in the model simultaneously, the service innovation aspect did not reach the expected significant, in which result the overall transformation level effect.

\section{Summary}

Information technology capabilities play a role in the development of services for manufacturers. The development of innovative service activities, manufacturers rely on information technology capabilities which designing and communicating with customer interface, and establishing the service of delivery system and the development of new service concept. Manufacturers invest in information technology infrastructure and establish the organizational structure of information technology. It can help enterprises to provide service management activities. Manufacturers can achieve goals of business transformation through service innovation. The provision of services has a positive and significant impact on the design of internal processes and enterprise network relationships. But it is relatively low impact on the enterprise category. Services impact within the enterprise is comprehensive, but it will not immediately change the status of enterprises in the industry. Because it must have more resources that can provide more complex services and content. 


\section{References}

[1] LU Nan. The Development trend and strategy of China's service economy. Journal of Hebei North University (Social Science Edition).2014.05. (In Chinese)

[2] Huang Yongming, Huo Jingdong. Research on System Innovation to Promote Service Economy Development in China. Scientific Development, 2010.6.(In Chinese)

[3] Abe, T. The development of service science. The Japanese Economy, 2005(33):55-74.

[4] Chesbrough, H. and Spohrer, J. Services science: A Research Manifesto. Communication of the ACM, 2006(49):35-40.

[5] Hidaka, K.Trends in services sciences in Japan and abroad. Quarterly Review, 2006(19):35-47.

[6] Abe, T.What is service science?. The Fujitsu Research Institute Economic Research Center, Tokyo, Japan. 2005.

[7] Hertog, P. D. Knowledge Intensive Business Services as Co-producers of Innovation [J].International Journal of Innovation Management .2000(4):491-528.

[8] Venkatraman, N. IT-enabled business transformation: From automation to business scope redefinition. Sloan Management Review, 1994(35):73-87.

[9] Gonzalez, J.V. and Garazo, T.G. Structural Relationships between Organizational Service Orientation, Contact Employee Job Satisfaction and Citizenship Behavior. International Journal of Service Industry Management, 2006(17):23-50.

[10]Council on Competitiveness. Innovate America: Thriving in a World of Challenge and Change[R].NY, USA.2005:120.

[11]Horn, P. The new discipline of services science: It's a melding of technology with an understanding of business processes and organization -and it's crucial to the economy's next wave. Business Week, 2005, January 21.

[12] Shaheen, G. T. Approach to transformation. Chief Executive, 1994(3):2-5. 